\title{
INFLUENCE OF THE MATRIX OF AQUEOUS SOLUTIONS ON THE ADSORPTION OF ENDOCRINE DISRUPTORS BY FULLERENE C60
}

\author{
Ion $\mathrm{ION}^{1}$, Raluca Madalina SENIN ${ }^{1,2}$, Bogdan VASILE ${ }^{1}$, Alina Catrinel ION ${ }^{1^{*}}$ \\ ${ }^{1}$ Department of Analytical Chemistry and Environmental Engineering, \\ Faculty of Applied Chemistry and Material Science, "Politehnica" University of Bucharest, \\ 1 Polizu St., 011061 Bucharest, Romania \\ ${ }^{2}$ Department of Analysis, Tests, and Testings, National Research \& Development Institute for Chemistry and \\ Petrochemistry ICECHIM, 202 Splaiul Independentei St., 060021 Bucharest, Romania
}

Received 05 November 2018; accepted 29 November 2018

\begin{abstract}
In this work, fullerene (C60) was selected as a model carbon nanomaterial, humic acid (HA) as the model natural organic matter and bisphenol A (BPA), as a moderate hydrophobic organic contaminant. The effects of ionic strength, concentration of organic matter and of the $\mathrm{pH}$ over the adsorption of BPA on C60 were studied, as well as the competition between the BPA and the HA at the active sites of the C60. A possible adsorption mechanism was proposed as well as an attempt to study the sorption process in real environmental samples with characteristics alike to the optimum ones found in the synthetic samples studied.
\end{abstract}

Keywords: water pollution, environmental monitoring, fullerene C60, adsorption isotherms, endocrine disruptors.

\section{Introduction}

Understanding the interactions between carbon based nanomaterials (Mauter \& Elimelech, 2008) and organic and inorganic contaminants (Hou et al., 2017) in welldispersed solutions is helpful to follow their transport in aquatic environments (L. Wang, Hou, X. Wang, \& Chen, 2014). Carbon nanomaterials have several applications, among which removal of environmental contaminants might present beneficial environmental (Huffer, Kah, Hofman, \& Schmidt, 2013), or less beneficial eco toxicological impact (Zhou, Luo, Zhong, Yang, \& Chen, 2014). Their fate in natural waters depends on several factors, among which the chemical properties of the aqueous media are very important (Yang et al., 2013; A. C. Ion, I. Ion, \& Culetu, 2011). Fullerene C60 occurs also naturally, so it is important to study them as suitable models for other carbonaceous sorbents, which can be applied in the management of organic and inorganic pollutants (Kah, Zhang, \& Hofmann, 2014). Even if many applications of fullerene as sorbents for environmental contaminants from aqueous solutions were proposed, in natural waters their aggregates, heterogeneous in particle size limit their sorption properties, as well as the natural or synthetic media where they are applied.
Despite the high degree of conjugation, C60 behave chemically and physically as an electron-deficient alkene, rather than as an electron-rich aromatic system. C60 is a very hydrophobic molecule and it cannot be dissolved in polar solvents. It is sparingly soluble in alkanes its solubility increasing, as the length of the hydrocarbon chain increases, but it is soluble in aromatic solvents and carbon disulphide due to the $\pi-\pi$ interactions. C60 is highly electronegative and it readily acts as an electron acceptor in charge-transfer complexes. As a result, C60 can easily be dissolved by solvents that provide a free pair of electrons. The solubility of C60 increases in aromatic solvents with electron donating atoms such as pyridine. Inorganic solvents exhibit the same trend, solubility of C60 increasing in solvents in which they can form donor-acceptor complexes.

Bisphenol A (BPA) is an organic compound, well known as an endocrine disruptor (Pahigian \& Zuo, 2018; Prossnitz \& Barton, 2014), used as plasticizer in the production of polycarbonates and epoxy resins, applied in contact lenses, medical equipment, packages and electronic equipment. BPA is a white powder, moderately soluble in water, with values of its solubility between $120-150 \mathrm{mg} / \mathrm{L}$. The structure of fullerene C60 and

${ }^{\star}$ Corresponding author. E-mail: ac_ion@yahoo.com 
the structure of the studied endocrine disruptor BPA are presented in Figure 1.

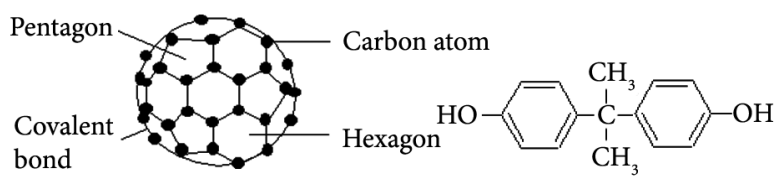

Figure 1. Structures of fullerene C60 and of bisphenol A (BPA)

The low solubility of C60 in water $\left(<10^{-9} \mathrm{mg} / \mathrm{L}\right)$ is well accepted, as mentioned before, but in contact with water, C60 can aggregate by forming stable colloidal suspensions, usually named in the literature $n \mathrm{C} 60$. There are several reported methods to disperse $\mathrm{C} 60$ in water, such as are sonication methods, organic solvent exchange and simple stirring of C60 powder in water (the aqua method) (SuZhen, Holger, \& Chen-Xu, 2014).

In the last years, the effects of natural organic matter (NOM) (L. Zhang, Y. Zhang, X. Lin, Yang, \& D. Lin, 2014), the $\mathrm{pH}$ and ionic strength of the solution (Deguchi, Alargova, \& Tsujii, 2001) were studied over the fullerene behaviour as sorbents for bisphenol A (BPA) (Zhou, Zhu, Zhang, \& Pan, 2015). The effect of humic acid (HA) and of the ionic strength (Huffer, Sun, Kubicki, Hofmann, \& Kah, 2017) over BPA sorption on fullerene C60 were investigated, being observed that electrostatic and hydrophobic interactions represent the main adsorption mechanisms (Yang, Li, Chen, Zhang, \& Xing, 2016). In order to improve the adsorptive performances and overcome the disadvantages of using carbon nanomaterials as environmental sorbents, these were combined with sand, or different types of soils, data being already mentioned in the literature (Liu et al., 2013).

In this work, fullerene (C60) was applied as a model carbon nanomaterial, humic acid (HA) as the model natural organic matter and bisphenol A as a moderate hydrophobic endocrine disruptor to investigate the influence of humic substances on the sorption of BPA on carbon nanomaterials in ternary systems (Song et al., 2017). Data concerning the reduced toxicity of the studied carbon nanomaterials were already published by our team (Ion et al., 2013). The less environmental damaging method of dispersion was chosen, involving a long-term mixing of C60 in water for a period of days, without the presence of organic solvent (Hyung \& Kim, 2009). Due to this tendency to form stable suspensions, nC60 can be readily available in natural systems and its behaviour in aqueous systems must be studied.

The effects of ionic strength, concentration of organic matter and of the $\mathrm{pH}$ over the adsorption of BPA on C60 in ternary systems containing HA were studied, as well as the competition between the BPA and the HA at the active sites of the C60, based on the suggested possible interactions described in the literature between the molecule of HA and organic contaminant (Gu et al., 2018; Li, Liu, Zhang, Wen, \& Wang, 2018). A possible adsorption mechanism was also proposed.

\section{Materials and methods}

\subsection{Materials}

The adsorbent used in this study was fullerene C60 (purity > 99 \%) obtained from Aldrich Chemical Co. Bisphenol A (BPA), (minimum purity 99\%) was obtained from Fluka/ Sigma-Aldrich Chemical, Germany. HPLC grade methanol was purchased from VWR Chemicals, France. Stock reference solutions were individually prepared in methanol and kept in the refrigerator for not more than one month. All working reference solutions were freshly prepared prior to use. Aqueous solutions were prepared using HPLC grade water.

\subsection{Preparation of BPA solutions}

The concentrated stock standard of $100 \mathrm{mg} / \mathrm{LBPA}$ was prepared in amber volumetric flasks, using methanol as solvent. The stock solution was stored at $2-8^{\circ} \mathrm{C}$ up to one week. The working standard solutions were daily prepared by diluting aliquots of the concentrated stock standard into volumetric flasks containing HPLC grade water.

For the quantification of bisphenol A, an external standard calibration method was used. The calibration curve was constructed by plotting the peak areas of BPA from the chromatograms of the working standard solutions versus the concentration of analyte per sample. The concentration range of the linearity range of the calibration curve was between $1 \mathrm{mg} / \mathrm{L}$ and $60 \mathrm{mg} / \mathrm{L} \mathrm{BPA}$.

\subsection{Preparation of aqueous suspension of $\mathbf{n C 6 0}$}

The solutions were prepared in single phase mixing by adding $1 \mathrm{mg}$ of C60 in $100 \mathrm{~mL}$ between $1 \mathrm{~g} / \mathrm{L}$ and $10 \mathrm{~g} / \mathrm{L}$ aqueous solution of $\mathrm{NaCl}$ and $10-30 \mathrm{mg} / \mathrm{l}$ humic acid (HA) using a modified method from the literature (Brant, Labille, Bottero, \& Wiesner, 2006). The suspensions were continuously mixed with a magnetic stirrer for 24 hours. Aliquots were sampled after 0.5, 1, 2, 12 and 24 hours, filtered through $0.45 \mu \mathrm{m}$ filters (Fisher Scientific Denver $\mathrm{CO})$ to remove the undispersed material. The concentration of nC60 in water was determined by UV absorption spectrometry (Andrievsky, Klochkow, Bordyuh, \& Dovbeshko, 2002) at $347 \mathrm{~nm}$ using a UV-Vis CINTRA 202 spectrophotometer, the UV-Vis absorbance spectra of the nC60 suspensions showing a characteristic absorbance peak of solvated C60 located at this wavelength. Broad band absorption between 400 and $550 \mathrm{~nm}$ might indicate the presence of aggregated forms of C60 (Chen \& Elimelech, 2007).

\subsection{Quantitative Analysis of dispersed C60 in aqueous solutions}

The concentration of C60 aggregates was spectrophotometric determined (Zhou et al., 2015). A $10 \mathrm{mg} / \mathrm{L}$ C60 stock solution was prepared by dispersing $1 \mathrm{mg}$ of $\mathrm{C} 60$ in $100 \mathrm{~mL} 1-10 \mathrm{~g} / \mathrm{L} \mathrm{NaCl}$ aqueous solution and $10-30 \mathrm{mg} / \mathrm{L}$ humic acid (HA) for 30 minutes in an ultrasonic bath at 
room temperature. The standard working solutions of 2 , 4,6 and $8 \mathrm{mg} \mathrm{C60/L} \mathrm{were} \mathrm{obtained} \mathrm{by} \mathrm{diluting} \mathrm{the} \mathrm{ap-}$ propriate volumes of the stock solution. The absorbance of the working solutions was measured at $347 \mathrm{~nm}$, by scanning between $300-800 \mathrm{~nm}$ in $10 \mathrm{~mm}$ quartz cuvettes using a UV-Vis CINTRA 202 spectrophotometer. $\mathrm{NaCl}$ aqueous solutions of $1-10 \mathrm{mg} / \mathrm{l}$ concentration were used as background. The concentration of C60 aggregates was determined by fitting the measured spectrum to calibrated reference spectra.

\subsection{HPLC analytical conditions}

HPLC determinations were performed using an Agilent 1100 Series HPLC instrument, equipped with a quaternary pump, a degasser, an auto sampler, an UV-DAD detector and Agilent Chemstation software for data acquisition and analysis (Radu et al., 2016). The chromatographic parameters were: injection volume: $10 \mu \mathrm{L}$; run time: $8 \mathrm{~min}$; column temperature: $25^{\circ} \mathrm{C}$; column: stationary phase: $\mathrm{C} 18$ (Zorbax Eclipse Plus-Agilent), $3.5 \mu \mathrm{m}, 100 \times 4.6 \mathrm{~mm}$ i.d.; flow rate: $0.5 \mathrm{~mL} / \mathrm{min}$, isocratic conditions at $80: 20(\mathrm{v} / \mathrm{v})$, methanol:HPLC grade water. Prior to each series of chromatographic separations, the analytical column was conditioned for $30 \mathrm{~min}$ with methanol, and equilibrated with $(80: 20 \mathrm{v} / \mathrm{v})$ methanol: water mixture. A period of $10 \mathrm{~min}$ of equilibration was required before the next injection. DAD detector performed monitoring of BPA at $280 \mathrm{~nm}$. Identification was made by comparing this time with the retention time $\left(t_{R}\right)$ of BPA from standard solution.

\subsection{Batch adsorption experiments}

The adsorption experiments were done in synthetic and in natural aqueous solutions. The synthetic solutions with different concentrations of BPA were obtained by dilution of the standard solution of $100 \mathrm{mg} / \mathrm{L} \mathrm{BPA}$ in 1-10 g/L aqueous solutions of $\mathrm{NaCl}$ and $10-30 \mathrm{mg} / \mathrm{L} \mathrm{hu}-$ mic acid. $100 \mathrm{~mL}$ volumes of the prepared solutions were added in $100 \mathrm{ml}$ glass bottles, each containing $1 \mathrm{mg}$ of adsorbent, precisely weighed. The mixtures were placed in a water bath and there were shaken at $150 \mathrm{rpm}$. The solutions were filtered on $0.45 \mu \mathrm{m}$ PTFE syringe filters and the BPA concentration was chromatographically analysed. Several influences such as: the effect of contact time at different concentrations of carbon nanomaterials and of BPA, effect of the temperature and effect of $\mathrm{pH}$ were studied.

The BPA rate (\%) and adsorption capacity $(\mathrm{mg} / \mathrm{g})$ were calculated by the formula:

$$
q=\frac{C_{0}-C_{x}}{m} \times V,
$$

where: $q(\mathrm{mg} / \mathrm{g})$ is the BPAadsorption capacity $C_{0}(\mathrm{mg} / \mathrm{L})$ and $C_{x}(\mathrm{mg} / \mathrm{L})$ are the initial and equilibrium BPA concentrations in the solution, $V(\mathrm{~L})$ the solution volume, and $M(\mathrm{~g})$ the mass of adsorbent, respectively.

\subsection{Characterization of the nanosorbents}

BET specific surface areas and pore size distribution: The Brunauer-Emmet-Teller (BET) specific surface area of the samples was characterized by nitrogen adsorption using a Quantachrome NOVA 2200e instrument. Nitrogen adsorption/desorption isotherms were measured at the temperature of liquid nitrogen (77K). Prior to measurements, the samples were degassed at $150{ }^{\circ} \mathrm{C}$ in vacuum for $4 \mathrm{~h}$. The specific surface area was calculated according to the BET equation. The total pore volume was estimated from the amount of gas adsorbed at $p / p_{0}=0.99$. Pore size distribution was calculated from the desorption branch of the isotherm using Barrett-Joyner-Halenda (BJH) method (Zhao, Wang, Ghosh, \& Xing, 2014).

Transmission electron microscopy (TEM): Electron micrographs were obtained by Philips 120 transmission electron microscopy. TEM specimens were homogeneously dispersed by placing thin layers of fullerene suspension on conductive copper carbon grid surfaces and drying overnight at room temperature.

Fourier Transformed Infrared spectrometry (FTIR): The determinations were made using a FTIR spectrometer Vertex 70 Brucker equipped with a device for analysing solid samples by solid $\mathrm{KBr}$ of spectral purity using the pressed disc method. FTIR spectra were recorded between $4000-400 \mathrm{~cm}^{-1}$ with a resolution of $4 \mathrm{~cm}^{-1}$, in the same conditions being recorded and compared the spectrum pure $\mathrm{KBr}$.

\section{Results and discussion}

\subsection{Characterization of the nanosorbent}

FTIR analysis. FTIR spectra of simple and impregnated nanostructures are presented in Figure 2. C60 has 174 vibration modes, of which less than 42 are distinct. Only four modes render them IR-active. Fourier transform infrared (FTIR) spectra of C60 show these four bands at $1430,1182,577$, and $527 \mathrm{~cm}^{-1}$ as expected from symmetry considerations. In the FTIR spectra of C60, the peak at around $1445 \mathrm{~cm}^{-1}$ can be attributed to the carbon double bond from the benzene molecule. The skeleton vibration peaks of carbon double bond from the aromatic rings are found at 1523 and at $1633 \mathrm{~cm}^{-1}$.

After the BPA adsorption, new peaks appear in the spectra at $2800-3600 \mathrm{~cm}^{-1}$ and at $400-1800 \mathrm{~cm}^{-1}$, indicating the presence of oxygen containing groups: at $1200 \mathrm{~cm}^{-1}$ the $\mathrm{C}-\mathrm{OH}$ stretching, at 1700 and $3600 \mathrm{~cm}^{-1}$ the $\mathrm{O}-\mathrm{H}$ stretching. The peak corresponding to the skeleton vibration of the carbon double bond from the aromatic molecules is thinner and shifted at $1641 \mathrm{~cm}^{-1}$. This is a possible indication of the $\pi-\pi$ interactions between the benzene rings from the BPA molecule and the benzene rings from the C60. The HO- frequency is shifted from 3738 to $3455 \mathrm{~cm}^{-1}$, a large peak being associated with the hydrogen bond formation between the BPA molecule and oxygen containing groups from the surface of the nanostructures. 


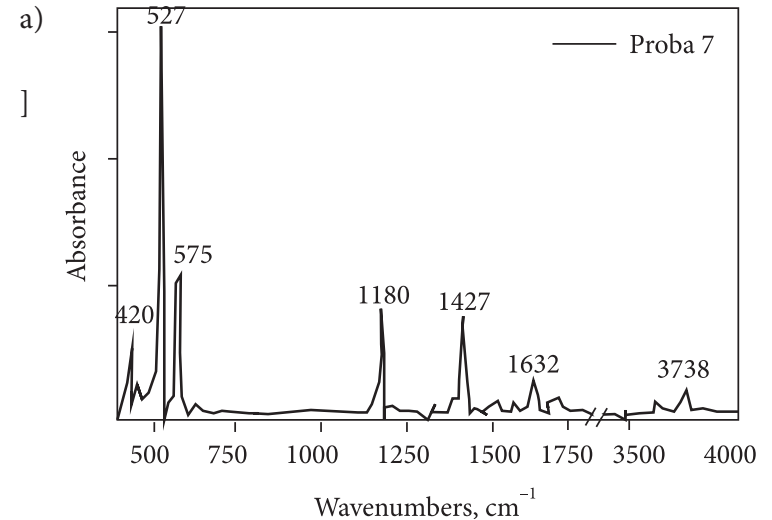

b)

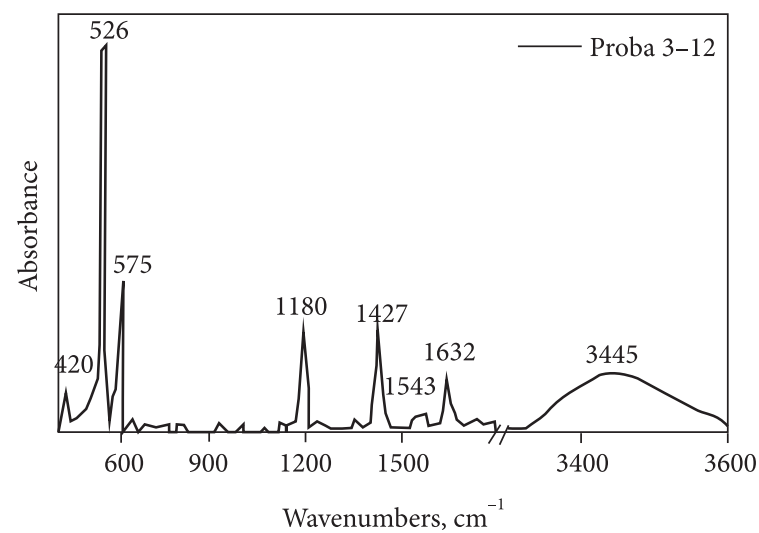

Figure 2. FTIR spectra of simple and impregnated nanostructures, a) $\mathrm{C} 60$ without $\mathrm{BPA}$, b) $\mathrm{C} 60$ with $\mathrm{BPA}$

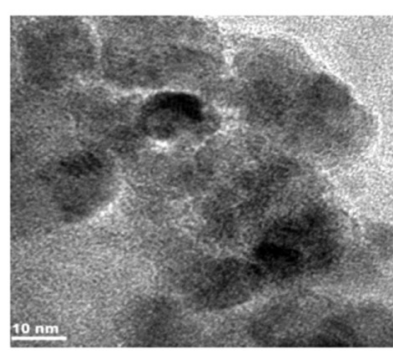

a)

Figure 3. The morphologies of the simple and impregnated C60, a) C60 with BPA, b) C60 without BPA (Senin et al., 2018)

TEM: The morphologies of the simple and impregnated C60 with BPA are presented in Figure 3, observing that $\mathrm{C} 60$ show a homogeneous distribution of the spheres.

TEM images show circular shape of C60 aggregates, with averaged diameters between 20-50 $\mathrm{nm}$. Comparing the simple and impregnated C60 with BPA by transmission electron microscopy, the presence of a compact layer that covers the surface with BPA might be observed, taking into account the dimensions of the BPA molecule around $10 \mathrm{~A}^{0}$. The interaction of BPA through hydrogen bonds with the surface of the nanotubes may be with one hydroxyl group and $\pi-\pi$ interaction, or through two hydrogen bonds with both hydroxyl groups, but without $\pi-\pi$ interaction (Senin et al., 2018). a)

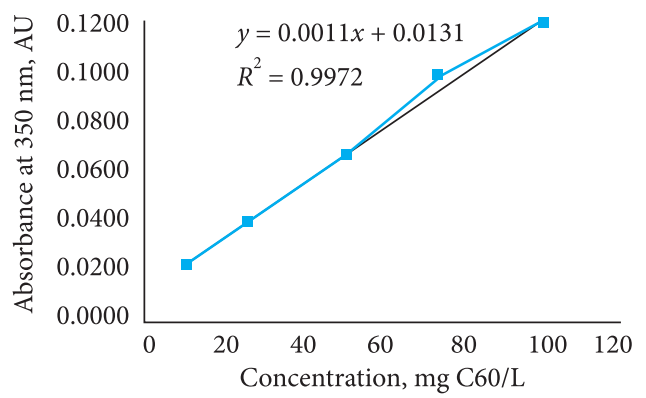

b)

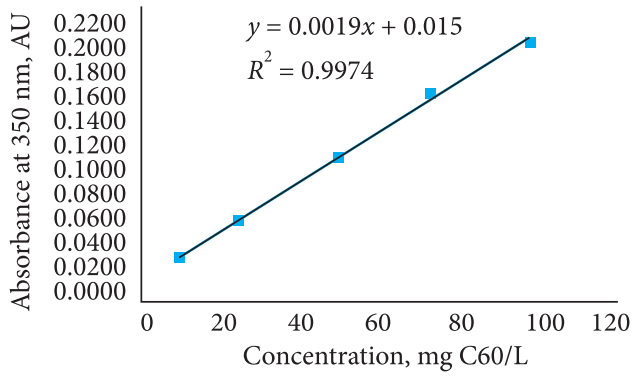

Figure 4. Calibration curves of the C60 suspensions in water (a), humic acid $30 \mathrm{mg} / \mathrm{L}$ and $0.01 \mathrm{M} \mathrm{NaCl}$ (b)

\subsection{Quantitative Analysis of dispersed C60 in aqueous solutions}

Quantitative Analysis of dispersed C60 in aqueous solutions is represented below (Figure 4), by the calibration curves spectrophotometric determined in several environmental matrices.

\subsection{BPA adsorption isotherms}

In environmental applications, adsorptive capacity depends on several other factors, such as ionic strength, temperature and $\mathrm{pH}$, especially connected with the structure of the organic sorbate. In order to describe the equilibrium adsorption of BPA on C60 aggregates mimicking environmental conditions, non-linear Langmuir and Freundlich isotherms were used (Gotovac et al., 2006). The interrupted lines represent the fitting curves using Freundlich and Langmuir models at the three studied temperatures (Figure 5). The values of the Freundlich and Langmuir adsorption parameters were calculated.

\subsubsection{Effect of the ionic strength}

The effect of ionic strength over the degree of adsorption of the studied organic contaminants on the carbon nanostructures was preliminary studied, variation of the sorption capacities being noticed in the presence of some inorganic salts or natural organic matter. The equilibrium data were fitted with Langmuir and Freundlich models (Figure 6). It was observed that the critical coagulation

It was observed that the critical coagulation concentration (CCC) of nC60 presents different values, at $0.142 \mathrm{M}$ $\mathrm{NaCl}$ in the absence of humic acids. The values of $\mathrm{NaCl}$ concentration in the studied solutions were below the critical coagulation concentration, being observed closer the value of the ionic strength is to the CCC, lower are the 
a)

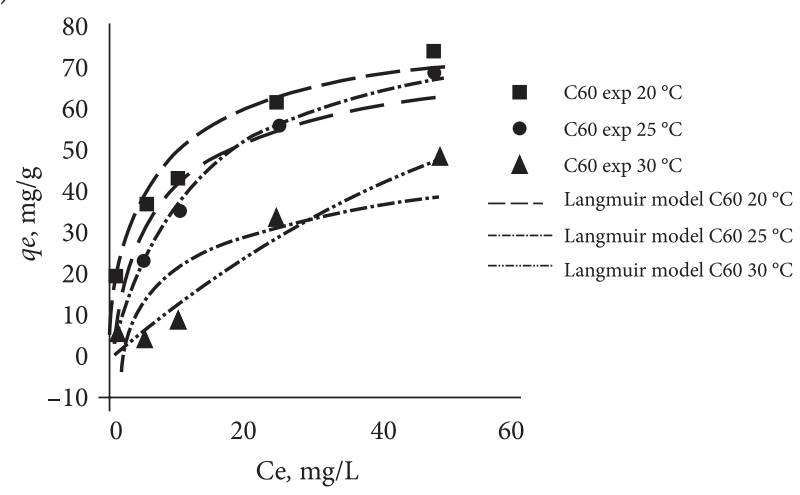

b)

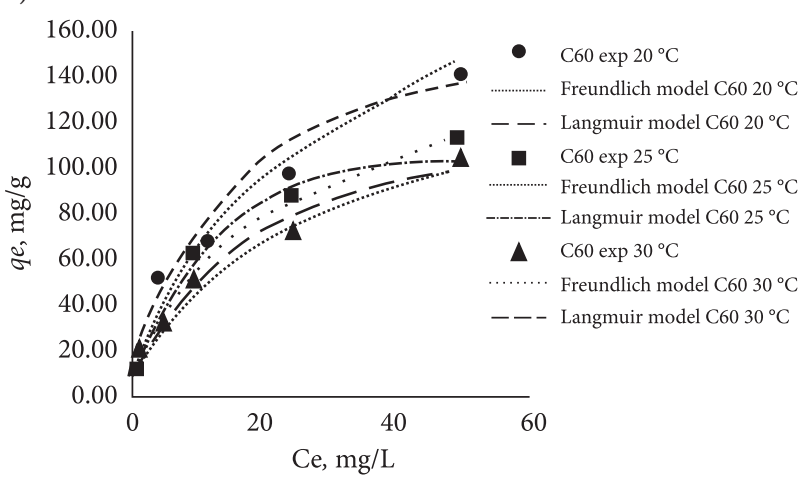

Figure 5. Langmuir 4 and Freundlich non-linear adsorption isotherms of BPA on $\mathrm{C} 60$; Conditions: $\mathrm{Ci}=10-50 \mathrm{mg} / \mathrm{L} \mathrm{BPA}$, $\mathrm{t}=20,25,30^{\circ} \mathrm{C}, \mathrm{V}=100 \mathrm{~mL}, 0.1 \mathrm{M} \mathrm{NaCl}(\mathrm{a})$ and $0.01 \mathrm{M}$ $\mathrm{NaCl}(\mathrm{b})$, contact time 3 hours, equilibrium reached after 30 minutes

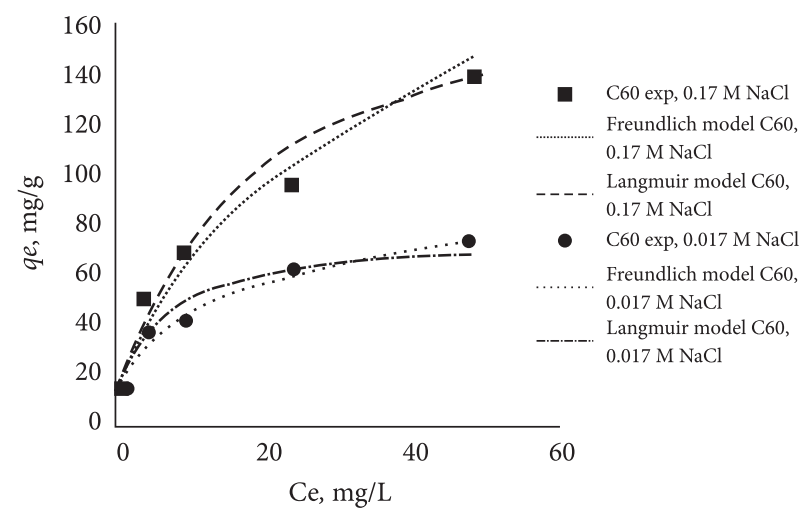

Figure 6. Comparison of the maximum sorption capacity of $\mathrm{C} 60$ for BPA in aqueous solutions, $0.01 \mathrm{M}$ and $0.1 \mathrm{M} \mathrm{NaCl}$
Langmuir predicted maximum sorption capacities $q_{m}$ of $\mathrm{nC60}$ for BPA, $74.44 \mathrm{mg} / \mathrm{g}$ in $0.1 \mathrm{M} \mathrm{NaCl}$ and $185.9 \mathrm{mg} / \mathrm{g}$ in $0.01 \mathrm{M} \mathrm{NaCl}$ in saline aqueous solutions in the absence of humic acids.

Experimental data show that in $\mathrm{NaCl}$ aqueous solutions of concentrations between $0.01-0.05 \mathrm{M}$, the adsorption of organic contaminants increases, probably due to a better contact of the non-planar molecules of BPA with the carbon nanostructures. Distribution of the $\mathrm{Na}^{+}$and $\mathrm{Cl}^{-}$ions between the negatively charged fullerenes increases the distance between the surfaces, facilitating the access at the surface of the organic molecules.

The isotherm parameters for the adsorption of BPA on C60 at different temperatures, at $0.1 \mathrm{M}$ and $0.01 \mathrm{M} \mathrm{NaCl}$ aqueous solutions are listed in Table 1.

The presence of higher concentrations of $\mathrm{NaCl}$ $(\sim 0.1 \mathrm{M})$ in solution decreases the solubility of BPA $\left(120 \mathrm{mg} / \mathrm{L}\right.$ la $25^{\circ} \mathrm{C}, \log \mathrm{Kow}=3.2$ la $\left.25^{\circ} \mathrm{C}\right)$, facilitating its affinity for the hydrophobic surfaces of the carbon surface and increases also the dimensions of C60 aggregates by reducing the electrostatic energy barrier and leading to faster aggregation.

The increase of $\mathrm{Na}^{+}$concentration could reduce the electrostatic energy barrier, leading to fast aggregation in reaction controlled regime, till the critical coagulation concentration. Then the energy barrier is eliminated and the diffusion controlled aggregation began. Even so, the noticed differences between the values of $q_{m}$ as predicted by Langmuir models in the temperature range $20-30{ }^{\circ} \mathrm{C}$ might be due to the increase of the hydrodynamic size of $\mathrm{nC60}$ at different concentrations of $\mathrm{NaCl}$ in the absence of humic acids.

The effect of the ionic strength over the $q_{m}$ values of the adsorption isotherms of BPA on C60 is presented in Figure 7.

The values of $q_{m}$ do not vary much in the range of 0-25 $\mathrm{mM} \mathrm{NaCl}$, indicating that the influence of salinity has slight effect on the sorption of BPA. At salinity values higher than $50 \mathrm{mM} \mathrm{NaCl}$, deposition of C60 appear, revealing that higher salinity values might represent the cause of the deposition of nC60 prepared from filtered solutions. The electrostatic interactions and the specific ones between the sorbate and the sorbent are more important than those between BPA and the curved surface of the carbon nanostructures. Hydrogen bonds might appear between the hydroxyl groups of BPA and the surfaces of C60.

Table 1. Isotherm parameters for the adsorption of BPA on C60

\begin{tabular}{|c|c|c|c|c|c|c|c|c|c|c|c|c|}
\hline \multirow{3}{*}{$\mathrm{T},{ }^{\circ} \mathrm{C}$} & \multicolumn{3}{|c|}{ Langmuir } & \multicolumn{3}{|c|}{ Freundlich } & \multicolumn{3}{|c|}{ Langmuir } & \multicolumn{3}{|c|}{ Freundlich } \\
\hline & $\begin{array}{c}q_{m} \\
\mathrm{mg} / \mathrm{g}\end{array}$ & $\begin{array}{c}K_{L}, \mathrm{~L} / \\
\mathrm{mg}\end{array}$ & $R^{2}$ & $K_{F}$ & $n$ & $R^{2}$ & $\begin{array}{c}q_{m} \\
\mathrm{mg} / \mathrm{g}\end{array}$ & $\begin{array}{c}K_{L}, \mathrm{~L} / \\
\mathrm{mg}\end{array}$ & $R^{2}$ & $K_{F}$ & $n$ & $R^{2}$ \\
\hline & \multicolumn{6}{|c|}{$\mathrm{NaCl}, 0.1 \mathrm{M}$} & \multicolumn{6}{|c|}{$\mathrm{NaCl}, 0.01 \mathrm{M}$} \\
\hline 20 & 74.44 & 0.0180 & 0.9174 & 27.68 & 2.12 & 0.9628 & 185.09 & 0.0644 & 0.9886 & 21.92 & 2.04 & 0.9246 \\
\hline 25 & 20.07 & 0.0860 & 0.9781 & 20.74 & 1.36 & 0.8803 & 140.73 & 0.0981 & 0.9882 & 21.69 & 2.33 & 0.9803 \\
\hline 30 & 10.09 & 0.0507 & 0.9990 & 9.45 & 1.87 & 0.7237 & 134.74 & 0.0624 & 0.9656 & 15.57 & 2.02 & 0.9200 \\
\hline
\end{tabular}




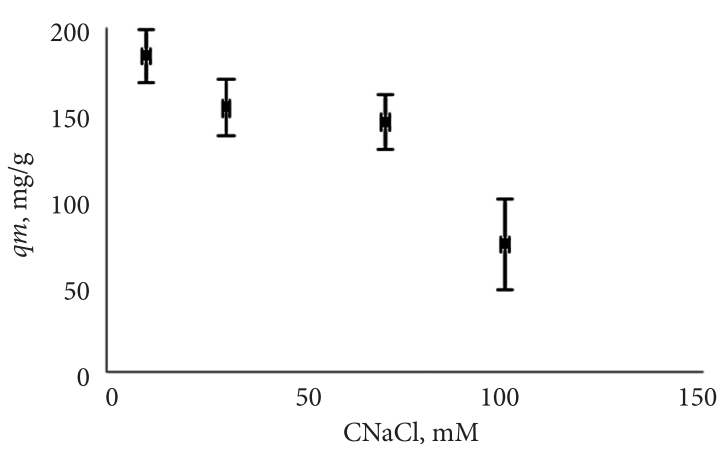

Figure 7. Effect of the ionic strength over the $q_{m}$ values of the adsorption isotherms of BPA on $\mathrm{C} 60,20^{\circ} \mathrm{C}$

\subsubsection{The effect of humic acid concentration over the adsorption of BPA on C60}

In natural ternary systems containing $\mathrm{HA}$, several interactions are indicated in the literature (Zhang, Liu, Li, Chen, \& Wang, 2018). Among them, there might be mentioned the formation of ternary surface complexes between the carbon surface-HA-BPA, in which HA acts as a binding bridge between the BPA molecule and the carbon surface of the nanomaterial and the direct interaction between the BPA and the HA molecules.

The equilibrium data were fitted with Langmuir and Freundlich models, as shown in Figure 8. The adsorption of BPA was non-linear and it fitted well the Langmuir model. The presence of HA suppresses the adsorption of BPA onto the C60 aggregates and the degree of inhibition increased by increasing the HA concentration.

The effect of several concentrations of HA between 10 and $50 \mathrm{mg} / \mathrm{l}$ was studied over the sorption capacity of nC60. From previous spectrophotometric studies it was observed that the degree of dispersion of nC60 is constant in the first 30 minutes, after 10 minutes of sonication at $240 \mathrm{~W}$ and $40 \mathrm{kHz}$. During shaking for 2 days at $150 \mathrm{rot} /$ $\mathrm{min}$, at room temperature the solutions become transparent, suggesting severe agglomeration of the aqu nC60 aggregates. The results can be explained by the direct competition for the adsorption sites between HA and BPA, which made the adsorption of BPA onto the C60 surface more difficult. The presence of HA prevented the aqu/ $\mathrm{nC60}$ to form bigger aggregates as affected by $\mathrm{NaCl}$. The nC60 aggregated in all samples at higher concentrations of $\mathrm{NaCl}$ in the presence of humic acid. The aggregation
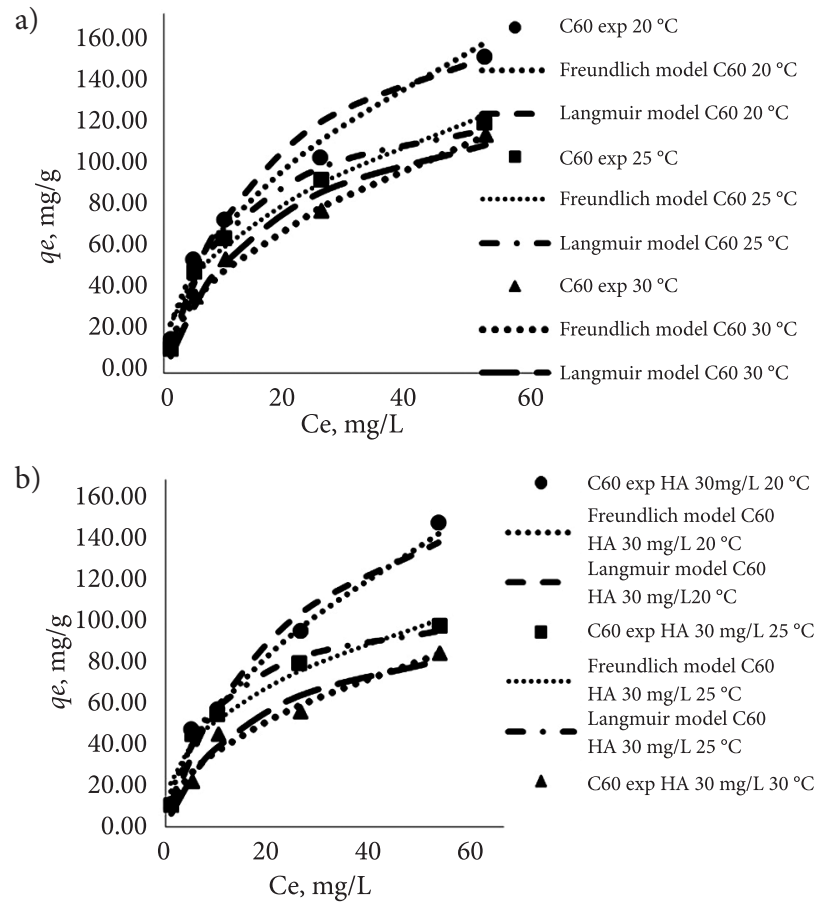

Figure 8. Langmuir 4 and Freundlich non-linear adsorption isotherms of BPA on C 60; Conditions: $\mathrm{Ci}=10-50 \mathrm{mg} / \mathrm{L} \mathrm{BPA}$,

$\mathrm{t}=20,25,30^{\circ} \mathrm{C}, \mathrm{V}=100 \mathrm{~mL}, 0.01 \mathrm{M} \mathrm{NaCl}, 10 \mathrm{mg} / \mathrm{L} \mathrm{HA}$

(a) and $30 \mathrm{mg} / \mathrm{L} \mathrm{HA} \mathrm{(b),} \mathrm{contact} \mathrm{time} 3$ hours, equilibrium reached after 30 minutes

rate decreased by increasing the HA concentration, correlated with the results of nC60 aggregation behaviour in water samples.

The isotherm parameters for the adsorption of BPA on C60 at different temperatures, HA $10 \mathrm{mg} / \mathrm{L}$ and $30 \mathrm{mg} / \mathrm{L}$ are listed in Table 2.

It can be also observed from Figures 7 and 8 that the presence of HA prevents the aggregation of $\mathrm{nC} 60$, as affected by the increase of the concentration of the salts in solution. The presence of HA increases the dispersion of aqu nC60suspensions for hours. For longer periods of time agglomeration appears in the presence of $\mathrm{HA}$, in the range of the studied concentrations.

Physical sorption is the dominant mechanism of sorption for pristine $\mathrm{C} 60$ in the case of BPA, the adsorption study showing rapid equilibrium rates, high adsorption capacity, low sensitivity to variations of $\mathrm{pH}$ and good fitting with Langmuir and Freundlich isotherm models of adsorption (Table 2).

Table 2. Isotherm parameters for the adsorption of BPA on C60

\begin{tabular}{|c|c|c|c|c|c|c|c|c|c|c|c|c|}
\hline \multirow{3}{*}{$\mathrm{T},{ }^{\circ} \mathrm{C}$} & \multicolumn{3}{|c|}{ Langmuir } & \multicolumn{3}{|c|}{ Freundlich } & \multicolumn{3}{|c|}{ Langmuir } & \multicolumn{3}{|c|}{ Freundlich } \\
\hline & $\begin{array}{c}q_{m} \\
\mathrm{mg} / \mathrm{g}\end{array}$ & $\begin{array}{c}K_{L}, \mathrm{~L} / \\
\mathrm{mg}\end{array}$ & $R^{2}$ & $K_{F}$ & $n$ & $R^{2}$ & $\begin{array}{c}q_{m} \\
\mathrm{mg} / \mathrm{g}\end{array}$ & $\begin{array}{c}K_{L}, \mathrm{~L} / \\
\mathrm{mg}\end{array}$ & $R^{2}$ & $K_{F}$ & $n$ & $R^{2}$ \\
\hline & \multicolumn{6}{|c|}{$\mathrm{HA} 10 \mathrm{mg} / \mathrm{L}$} & \multicolumn{6}{|c|}{ HA 30 mg/L } \\
\hline 20 & 184.36 & 0.0180 & 0.9974 & 27.68 & 2.12 & 0.9628 & 193.13 & 0.0433 & 0.9639 & 20.31 & 2.60 & 0.9948 \\
\hline 25 & 135.80 & 0.0860 & 0.9781 & 20.74 & 1.87 & 0.8803 & 147.22 & 0.1180 & 0.9230 & 16.06 & 1.82 & 0.9428 \\
\hline 30 & 100.09 & 0.0507 & 0.9190 & 9.45 & 1.36 & 0.7237 & 112.65 & 0.0600 & 0.9275 & 11.51 & 2.00 & 0.9150 \\
\hline
\end{tabular}




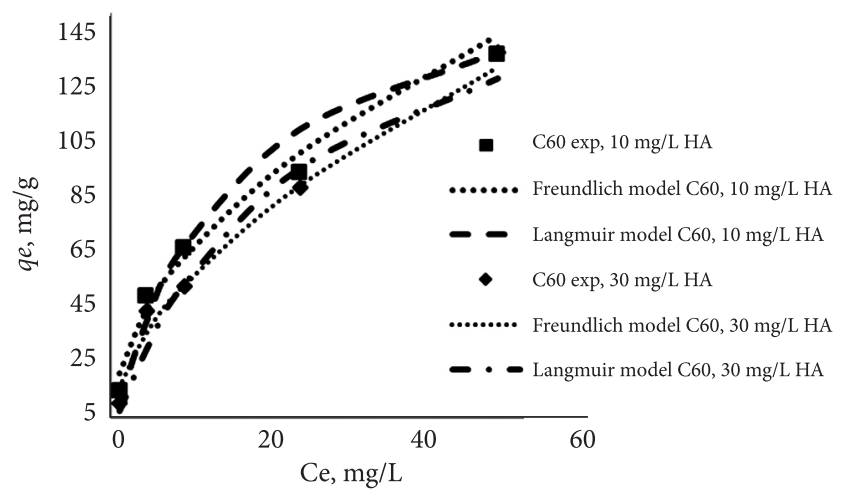

Figure 9. Comparison of isotherms of adsorption of C60 for $\mathrm{BPA}$ in aqueous solutions, $10 \mathrm{mM} \mathrm{NaCl}, 10$ and $30 \mathrm{mg} / \mathrm{L} \mathrm{HA}$

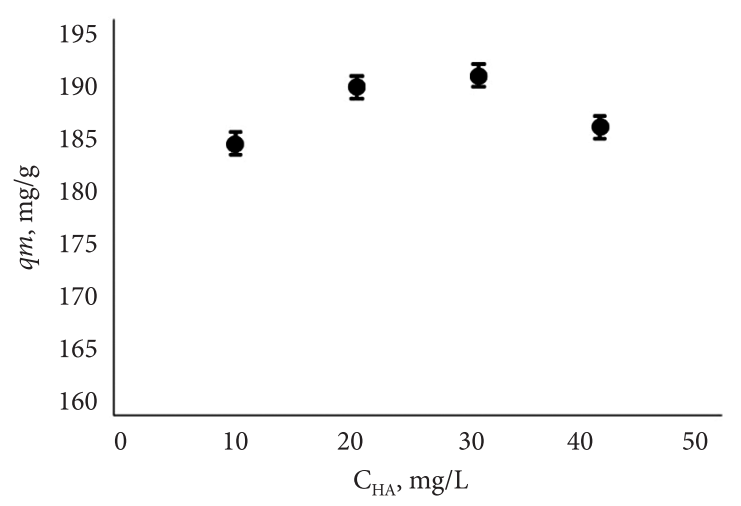

Figure 10. Effect of humic acid concentration over the $q_{m}$ values of the adsorption isotherms of BPA on C60, $10 \mathrm{mM} \mathrm{NaCl}, 20^{\circ} \mathrm{C}$

As shown in Figure 9, the maximum sorption capacity of nC60 decreases by increasing the concentration of humic acid in the aqueous solution. This might be possible due to the binding between nC60 and the molecules of humic acid, which reduces the number of binding sites available to BPA. The medium hydrophobic character of BPA must be also accounted.

The effect of humic acid over the $q_{m}$ values of the adsorption isotherms of BPA on C60 is presented in Figure 10 .

It was shown that the presence of humic acid prevented the C60 from forming bigger aggregates as affected by $\mathrm{NaCl}$. It might be supposed that the adsorption of HA molecules on C60 aggregates increase electrosteric repulsions and improve their stabilization. The presence of $\mathrm{NaCl}$ at low concentrations, $(<0.1 \mathrm{M})$ in environmental solutions does not severely influence the sorption of BPA in the presence of $30 \mathrm{mg} / \mathrm{l} \mathrm{HA}$.

\subsection{The effect of $\mathrm{pH}$ over the adsorption of BPA on C60}

The effect of $\mathrm{pH}$ over the adsorption capacity of fullerene C60 for BPA was investigated, being observed that the sorption process is stable in a broad range of $\mathrm{pH}$ values (Figure 11).

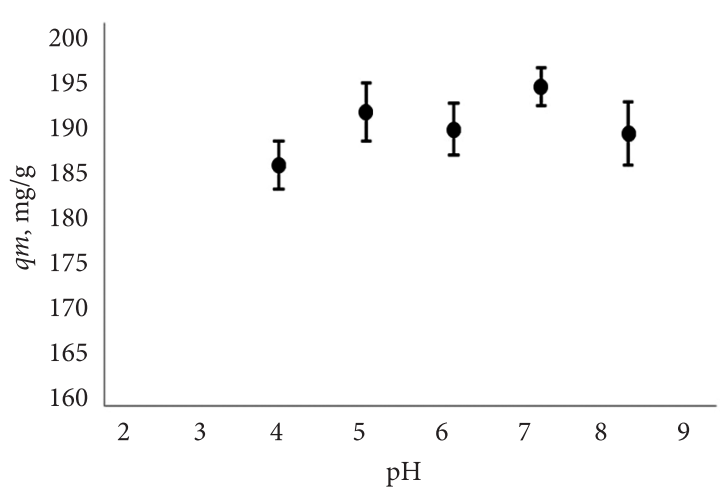

Figure 11. Influence of $\mathrm{pH}$ over the maximum sorption capacity of $\mathrm{C} 60$ for BPA in aqueous solutions, $10 \mathrm{mM} \mathrm{NaCl}, 30 \mathrm{mg} / \mathrm{L} \mathrm{HA}$

It is strongly influenced at very low $\mathrm{pH}$ values due to the aggregation of $\mathrm{C} 60$ based on the reactions of neutralization between the hydrogen ions and the acidic surfaces of C60. The presence of humic acids in the environmental aqueous solutions helps the stabilization of the fullerene C60, but suppresses the BPA adsorption because of the competitive interactions between the BPA molecules and the HA ones.

For $\mathrm{pH}$ values less than 4, the adsorption of BPA molecules on the nanostructures decreases possibly due to the formation of bigger aggregates, because of screening the surface charges of aqueous nC60 and to competitive interactions which suppress the BPA adsorption.

For $\mathrm{pH}$ values bigger than 7 , the hydrophobic interactions between the $\pi$ electrons of the graphite surface and the $\pi$ electrons of the $\mathrm{C}=\mathrm{C}$ double bonds from BPA decrease due to the BPA de-protonation reducing the degree of adsorption as well. The experimental results lead to optimum $\mathrm{pH}$ values between 6 and 7 for the impregnation experiments of BPA.

\subsection{Adsorption mechanism}

Sorption of organic contaminants to the C60 surface is driven by the same factors that influence sorption energies in conventional systems, such as: hydrophobicity, dispersion properties and weak polar forces, the $\pi-\pi$ bond being shown to be the dominant interaction for the adsorption of aromatic organic chemicals on C 60 (Keiluweit \& Kleber, 2009). The bond has been shown to be stronger for electron-donor-acceptor systems (EDA) in comparison with pairs of donors or of acceptors (Yang \& Xing, 2010). The tendency of C60 to form stable crystalline nanoparticles with diameters between $25-500 \mathrm{~nm}$ in diameter is explained by the Derjaguin-Landau-Verwey-Overbeek (DLVO) theory of colloidal stability and also by molecular dynamic studies (Zou, Zhang, Chen, \& Li, 2012).

Molecular self-assemblies of the C60 aggregates are based on non-covalent van der Waals, electrostatic and hydrophobic interactions that explain the behaviour of fullerene in aqueous solutions. Further solutions will be 
Table 3. Chemical composition of the studied saline waters

\begin{tabular}{|c|c|c|c|c|c|c|c|}
\hline Sample & $\begin{array}{c}\mathrm{Na}^{+} \\
(\mathrm{mg} / \mathrm{L})\end{array}$ & $\begin{array}{c}\mathrm{K}^{+} \\
(\mathrm{mg} / \mathrm{L})\end{array}$ & $\begin{array}{c}\mathrm{Ca}^{2+} \\
(\mathrm{mg} / \mathrm{L})\end{array}$ & $\begin{array}{c}\mathrm{Mg}^{2+} \\
(\mathrm{mg} / \mathrm{L})\end{array}$ & $\mathrm{Cl}^{-}(\mathrm{mg} / \mathrm{L})$ & $\begin{array}{c}\mathrm{SO}_{4}^{2-} \\
(\mathrm{mg} / \mathrm{L})\end{array}$ & $\begin{array}{c}\mathrm{NH}_{4}^{+} \\
(\mathrm{mg} / \mathrm{L})\end{array}$ \\
\hline P1 & 3803.77 & 97.59 & 41.16 & 478.71 & 1383.43 & 618.36 & 0.10 \\
\hline P2 & 3345.99 & 87.04 & 37.19 & 421.54 & 722.51 & 741.73 & 0.12 \\
\hline P3 & 2887.58 & 75.13 & 31.27 & 365.40 & 557.72 & 661.16 & 0.35 \\
\hline
\end{tabular}

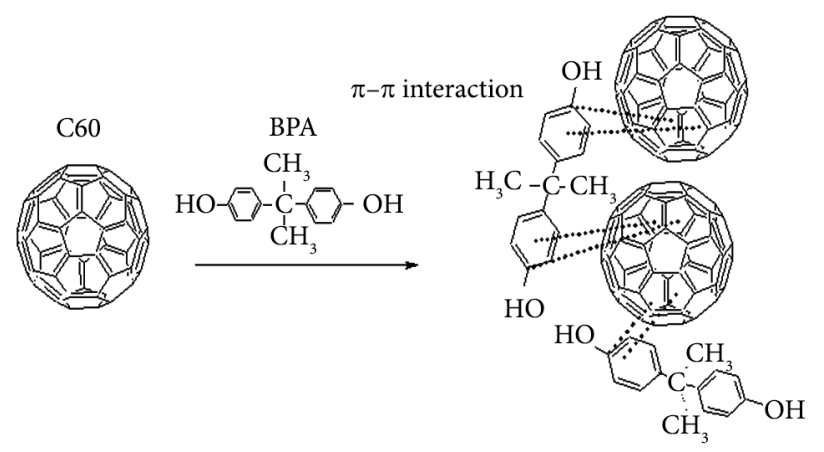

Figure 12. Adsorption mechanisms of BPA on C60

found for improving their solubility and reducing their agglomeration (Chen \& Elimelech, 2007). The main intermolecular forces appear between the benzene rings from the organic molecules and the carbon nanostructures (Figure 12), probably as $\pi-\pi$ interactions. The residual oxygen containing groups from the carbon nanostructures can also form hydrogen bonds with the hydroxyl groups from the BPA molecule. Between the studied molecules and the carbon nanostructures two main interactions seem to appear, one based on $\pi-\pi$ interactions and the other on the hydrogen bonds.

\subsection{Environmental applications of aqu/nC60 as sorbents for BPA in real water samples}

In order to verify the observations that have been done in synthetic solutions, three natural water samples and corresponding sediments were collected from a therapeutic area, in Dobrogea, Romania. The concentrations of BPA measured in the samples were lower than the detection limit of chromatographic method used in these experiments. The natural samples, the saline waters only and then the mixtures of saline waters and sediments were tested in the sorption experiments, by using the same experimental conditions: $\mathrm{Ci}=10-50 \mathrm{mg} / \mathrm{L} \mathrm{BPA}, \mathrm{T}=25^{\circ} \mathrm{C}$, $\mathrm{V}=100 \mathrm{~mL}$, the chemical composition of the natural samples (salts and sediments) being indicated in the tables below (Tables 3 and 4). The contact time was of 24 hours, the equilibrium was reached after 30 minutes.

Concentration values for several chemical parameters for naturally constituents present in the studied waters, $\mathrm{Na}^{+}, \mathrm{K}^{+}, \mathrm{Ca}^{2+}, \mathrm{Mg}^{2+}, \mathrm{F}^{-}, \mathrm{Cl}^{-}, \mathrm{Br}^{-}, \mathrm{SO}_{4}{ }^{2-}, \mathrm{NO}_{3}^{-}, \mathrm{NO}_{2}^{-}$, $\mathrm{PO}_{4}{ }^{3-}$ are shown in Table 3 . As it was expected, it is highlighted the character of the water, where high concentrations are observed for $\mathrm{Na}^{+}, \mathrm{Cl}^{-}, \mathrm{Mg}^{2+}$ and $\mathrm{SO}_{4}{ }^{2-}$, while for $\mathrm{K}^{+}, \mathrm{Ca}^{2+}$ and $\mathrm{Br}^{-}$these are in the order of a few tens.
Instead, concentrations of nitrates, nitrites and phosphates are rather low, since in some samples these were not determined, meaning that those values were lower than limit of detection.

Total carbon (TC) \%, total organic carbon (TOC) \% and inorganic carbon (IC) \% were analysed with an elemental analyser without any pre-treatment of the natural samples. It can be observed that the values are fairly constant. The equilibrium data for the sorption isotherms of BPA on C60 in natural aqueous solutions were fitted with Langmuir model, as shown in Figures 13 and 14.

The previous results showed that salinity between 0-100 $\mathrm{mM}$ in $\mathrm{NaCl}$ improves the sorption capacity of the $\mathrm{aqu} / \mathrm{nC60}$, the results obtained in natural saline waters confirming these ones. It can be observed that in natural saline waters maximum sorption capacity obtained from the Langmuir sorption model present values in the same range, probably due to the high concentrations of $\mathrm{NaCl}$ in the natural salts contained in the studied waters. Depending on the concentrations of $\mathrm{Ca}^{2+}$ and $\mathrm{Mg}^{2+}$ the values are slightly lower, because of the improved aggregation of

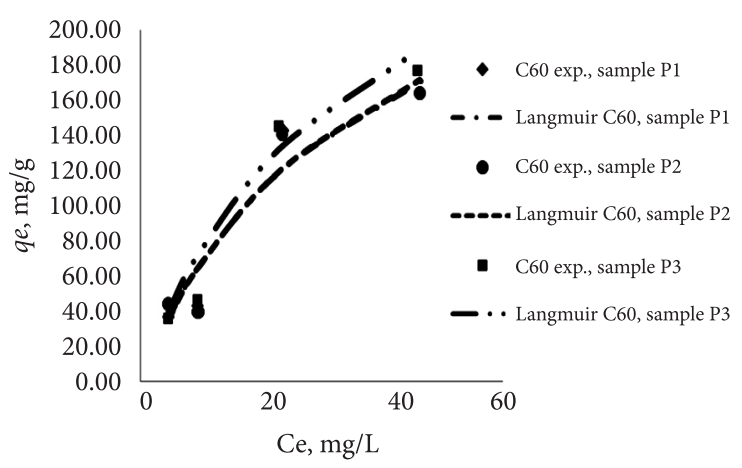

Figure 13. Comparison of the sorption isotherms of BPA on C60 in natural aqueous solutions, P1 - P3, ten times diluted

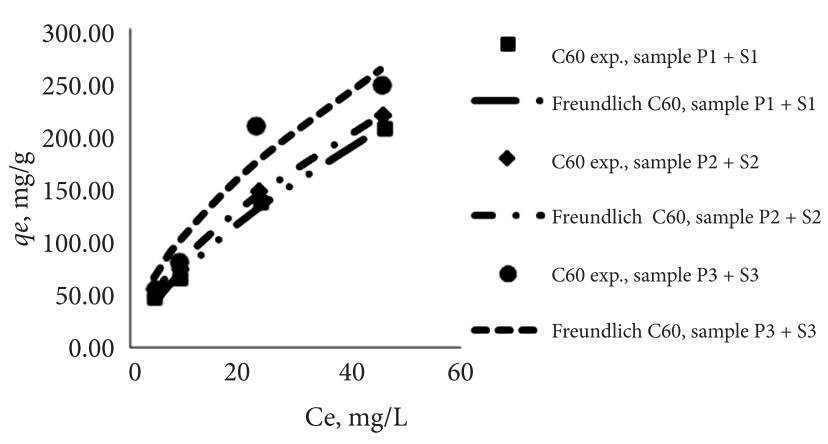

Figure 14. Comparison of the sorption isotherms of BPA on C60 in natural aqueous solutions, P1 - P3 and sediments $\mathrm{S} 1$ - S3, ten times diluted 
nC60 in the presence of divalent cations (Chen \& Elimelech, 2006; Duncan, Jinscheck, \& Vikesland, 2008; Hyung \& Kim, 2009). The sorption capacity of BPA at higher salt concentrations are shown in Figure 13, being observed that the maximum sorption capacity is reduced, probably because of the deposition of $\mathrm{nC} 60$, in correlation with the concentrations of divalent cations present in the salts. It is important to be mentioned that previous studies revealed also that higher salinities caused deposition of carbon nanostructures (Brant, Lecoanet, Hotze, \& Wiesner, 2005), in dependence with the valence of the cations. Several studies mentioned that ionic strength facilitate the aggregation of carbon nanomaterials (squeezing-out effect), suppressing the adsorption of organic hydrophobic compounds (Ji, Chen, Xu, \& Zheng, 2013). Increased ionic strength in connection with the valence of the cations present in the salts might also affect the adsorption of organic compounds due to the salting-out effect or electrostatic screening effect (Zhang, Shao, Bekaroglu, \& Karanfil, 2010).

Table 4. Physical parameters of the natural samples (sediments)

\begin{tabular}{|c|c|c|c|c|}
\hline 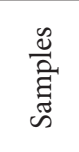 & $\begin{array}{c}\mathrm{H}_{2} \mathrm{O} \\
\left(105^{\circ} \mathrm{C}\right), \%\end{array}$ & $\begin{array}{c}\text { TC } \\
\text { (Total } \\
\text { Carbon), \% }\end{array}$ & $\begin{array}{c}\text { IC } \\
\text { (Inorganic } \\
\text { Carbon), \% }\end{array}$ & $\begin{array}{c}\text { TOC } \\
\text { (Total } \\
\text { Organic } \\
\text { Carbon), \% }\end{array}$ \\
\hline S1 & $3.87 \pm 0.02$ & $8.00 \pm 0.05$ & $6.71 \pm 0.16$ & $1.29 \pm 0.17$ \\
\hline S2 & $5.48 \pm 0.02$ & $8.27 \pm 0.05$ & $2.47 \pm 0.16$ & $5.80 \pm 0.17$ \\
\hline S3 & $4.94 \pm 0.02$ & $7.69 \pm 0.05$ & $3.95 \pm 0.16$ & $3.74 \pm 0.17$ \\
\hline Mean & $4.55 \pm 0.02$ & $7.52 \pm 0.05$ & $4.48 \pm 0.16$ & $3.03 \pm 0.17$ \\
\hline
\end{tabular}

Table 5. Values of the sorption capacity at equilibrium, for aqu/nC60 for BPA in the studied natural systems without sediment, temperature $25^{\circ} \mathrm{C}$, contact time 24 hours, equilibrium reached after 30 minutes, 10 times diluted

\begin{tabular}{|l|c|c|c|}
\hline Natural saline water & $q_{e}, \mathrm{mg} / \mathrm{g}$ & $\begin{array}{c}\mathrm{Mg}^{2+}, \\
\mathrm{mg} / \mathrm{L}\end{array}$ & TC, \% \\
\hline P1 & 106.67 & 0.030 & - \\
\hline P2 & 97.14 & 0.034 & - \\
\hline P3 & 110.49 & 0.026 & - \\
\hline $\begin{array}{l}\text { Model solution, with } \\
0.01 \mathrm{M} \mathrm{NaCl}\end{array}$ & 140 & - & - \\
\hline
\end{tabular}

Table 6. Values of the sorption capacity at equilibrium, for $\mathrm{aqu} / \mathrm{nC60}$ for BPA in the studied natural systems with sediment, temperature $25^{\circ} \mathrm{C}$, contact time 24 hours, equilibrium reached after 30 minutes, 10 times diluted

\begin{tabular}{|l|c|c|c|}
\hline $\begin{array}{c}\text { Natural saline water and } \\
\text { sediment }\end{array}$ & $q_{e}, \mathrm{mg} / \mathrm{g}$ & $\begin{array}{c}\mathrm{Mg}^{2+} \\
\mathrm{mg} / \mathrm{L}\end{array}$ & $\mathrm{TC}, \%$ \\
\hline $\mathrm{P} 1+\mathrm{S} 1$ & 143.33 & 0.030 & 8.27 \\
\hline $\mathrm{P} 2+\mathrm{S} 2$ & 117.14 & 0.034 & 7.69 \\
\hline $\mathrm{P} 3+\mathrm{S} 3$ & 118.57 & 0.026 & 8.00 \\
\hline $\begin{array}{l}\text { Model solution with } \\
10 \mathrm{mg} / \mathrm{L} \mathrm{HA}, 0.01 \mathrm{M} \mathrm{NaCl}\end{array}$ & 147.22 & - & 12 \\
\hline
\end{tabular}

The effect of the presence of sediments in the natural samples was also studied on the sorption of BPA on aqu/ nC60. As shown in Figure 14, the sorption capacity of in the sorption systems containing both aqu/nC60 and sediments previously characterized were higher in comparison with those in the sorption systems containing only aqu/ nC60. This results from the fact that both aqu/nC60 and sediments adsorbed BPA. It was already discussed in the literature (Hu, Liu, Mayer, \& Jiang, 2008) that the sorption capacity of carbon nanomaterials in the presence of humic acids for medium hydrophobic organic compounds are lower than the sum of sorption capacity for each of the involved sorbents. Our results confirm the conclusion; the sorption capacity of both aqu/nC60 and sediments was lower than the sorption capacity of each of them for BPA. This suggests that the sorption of BPA in combined system containing sediment and carbon nanostructure did not confirm the additive effect of sorption capacity for medium hydrophobic organic compounds (Li et al., 2013). This might be due to the binding between aqu/nC60 and humic organic compounds contained in the studied sediments indicated in the Table 4, that reduces the number of binding sites available to BPA.

The values of the equilibrium sorption capacity obtained in the studied natural aqueous systems, in the absence and in the presence of sediments are presented in Table 5 and 6 , being observed that these values are smaller than in synthetic solutions. Aqueous suspensions of nC60 were stable in the range of $\mathrm{pH}$ values from 3 to 11 , relevant to several aqueous media. It was also observed that the increase of salinity did not decrease the maximum sorption capacity in the presence of sediments, this being a result of the improved dispersion of aqu/nC60 in the presence of humic compounds from the sediments.

It is also possible that the electrostatic attraction between oppositely BPA and adsorbed HA may eventually compensate the suppression by HA.

\section{Conclusions}

$\mathrm{pH}$, ionic strength and dissolved organic matter alter aggregation of fullerene C60 nanoparticles suspensions in aqueous solutions. The nC60 remain relatively stable up to several hours under constant values of ionic strength, temperature and $\mathrm{pH}$. At values of the ionic strength, higher than $0.1 \mathrm{M}$ the size of aggregates increases involving drastically reduced sorption capacities for different contaminants.

The proposed adsorption mechanism presumes that the two benzene rings in BPA molecule attach to carbon atoms through a single bond, forming different angles. BPA molecule could groove on the fullerene surface because of its small diameter and spherical surface. The $\pi-\pi$ formed complex is a strong donor-acceptor system, the phenol group being a charge donor and the C60 an acceptor.

In the presence of humic acid, by increasing the values of ionic strength, the sorption capacity for the studied 
organic contaminant was moderately reduced, because the surface-bond HA increase the surface electronegativity of the $\mathrm{nC60}$, mitigating the aggregation through electrosteric repulsions.

The presence of HA suppresses the adsorption of BPA on $\mathrm{nC} 60$ in the studied conditions, fact that might be ascribed to competitive interactions between the two organic molecules on the surface of the studied carbon nanostructures.

It was also observed that in natural waters containing sediments with different compositions, at constant concentrations of total salt and sediment, the maximum sorption capacity of nC60 was influenced by the ratios of percent compositions of organic to inorganic carbon.

\section{Acknowledgements}

The research was performed in the frame of ERA-NET SIIN funded by the European Commission within the $7^{\text {th }}$ Framework Program and supported by the Romanian Executive Agency for Higher Education and RDI funding (Unitatea Executiva pentru Finantarea Invatamantului Superior, Cercetarii, Dezvoltarii si Inovarii: UEFISCDI).

\section{References}

Andrievsky, G. V., Klochkow, V. K., Bordyuh, A. B., \& Dovbeshko, G. J. (2002). Comparative analysis of two aqueous - colloidal solutions of C60 fullerene with help pf FTIR reflectance and UV-Vis spectroscopy. Chemical Physics Letters, 364, 8-17. https://doi.org/10.1016/S0009-2614(02)01305-2

Brant, J. A., Labille, J., Bottero, J., \& Wiesner, M. R. (2006). Characterization of the impact of preparation method on fullerene cluster structure and chemistry. Langmuir, 22, 3878-3885. https://doi.org/10.1021/la053293o

Brant, J., Lecoanet, H., Hotze, M., \& Wiesner, M. (2005). Comparison of electrokinetic properties of colloidal fullerene (nC60) formed using two procedures. Environmental Science and Technology, 39, 6343-6351. https://doi.org/10.1021/es050090d

Chen, K. L., \& Elimelech, M. (2006). Aggregation of and deposition kinetics of fullerene (C60) nanoparticles. Langmuir, 22(26), 10994-11001. https://doi.org/10.1021/la062072v

Chen, K. L., \& Elimelech, M. (2007). Influence of humic acid on the aggregation kinetics of fullerene C60 nanoparticles in monovalent and divalent electrolyte solutions. Journal of Colloids Interface Science, 309, 126-134. https://doi.org/10.1016/j.jcis.2007.01.074

Deguchi, S., Alargova, R. G., \& Tsujii, K. (2001). Stable dispersions of fullerenes C60 in water. Preparation and characterization. Langmuir, 17, 6013-6017.

https://doi.org/10.1021/la010651o

Duncan, K. L., Jinscheck, J. R., Vikesland, J. P. (2008). C60 colloid formation in aqueous systems: effects of preparation method on size, structure and surface charge. Environmental Science and Technology, 42(1), 173-178. https://doi.org/10.1021/es071248s

Gotovac, S., Hattori, Y., Nogoguchi, D., Miyamoto, J., Kanamaru, M., Utsumi, S., Kanoh, H., \& Kaneko, K. (2006). Journal of Physical Chemistry B, 110, 16219-16224.

https://doi.org/10.1021/jp0611830
Gu, P., Zhang, S., Li, X., Wang, X., Wen, T., Jehan, R., Alsaedi, A., Hayat, T., \& Wang, X. (2018). Recent advances in layered double hydroxide-based nanomaterials for the removal of radionuclides from aqueous solution. Environmental Pollution, 240, 493-505. https://doi.org/10.1016/j.envpol.2018.04.136

Hou, L., Fortner, J. D., Wang, X., Zhang, C., Wang, L., \& Chen, W. (2017). Complex interplay between formation routes and natural organic matter modification controls capabilities of C60 nanoparticles (nC60) to accumulate organic contaminants. Journal of Environmental Sciences, 51, 315-323.

https://doi.org/10.1016/j.jes.2016.07.009

Hu, X., Liu, J., Mayer, P., \& Jiang, G. (2008). Impacts of some environmentally relevant parameters on the sorption of polycyclic aromatic hydrocarbons to aqueous suspensions of fullerene. Nanomaterials in the environment, 27, 1868-1874. https://doi.org/10.1897/08-009.1

Huffer, T., Kah, M., Hofman, T., \& Schmidt, T. C. (2013). How redox conditions and irradiation affect sorption of PAHs by dispersed fullerene. Environmental Science and Technology, 47(13), 6935-6942. https://doi.org/10.1021/es303620c

Huffer, T., Sun, H., Kubicki, J. D., Hofmann, T., \& Kah, M. (2017). Interactions between aromatic hydrocarbons and functionalized C60 fullerenes - insights from experimental data and molecular modelling. Environmental science Nano, 4, 1045-1053. https://doi.org/10.1039/C7EN00139H

Hyung, H., \& Kim, J. H. (2009). Dispersion of C60 in natural water and removal by conventional drinking water treatment processes. Water Research, 43(9), 2463-2470. https://doi.org/10.1016/j.watres.2009.03.011

Ion, A. C., Bley, S., Ion, I., Culetu, A., Zahov, S., Hollert, H., \& Seiler, T. B. (2013). Investigation of the contaminant sorption of treated Romanian soils using "batch" and biological toxicity assays. Catena, 101, 205-211.

https://doi.org/10.1016/j.catena.2012.09.009

Ion, A. C., Ion, I., \& Culetu, A. (2011). Lead adsorption onto exfoliated graphitic nanoplatelets in aqueous solutions. $M a-$ terials Science and Engineering Series B: Solid State Materials for Advanced Technology, 176(6), 504-509. https://doi.org/10.1016/j.mseb.2010.07.021

Ji, L., Chen, W., Xu, Z., \& Zheng, S. (2013). Graphene nanosheets and graphite oxide as promising adsorbents for removal of organic contaminants from aqueous solutions. Journal of Environmental Quality, 42(1), 191-198. https://doi.org/10.2134/jeq2012.0172

Kah, M., Zhang, X. R., \& Hofmann, T. (2014). Sorption behavior of carbon nanotubes: changes induced by functionalization, sonication and natural organic matter. Science of Total Environment, 497, 133-138. https://doi.org/10.1016/j.scitotenv.2014.07.112

Keiluweit, M., \& Kleber, M. (2009). Molecular level interactions in soils and sediments: the role of aromatic pi-systems. Environmental Science and Technology, 43(10), 3421-3429. https://doi.org/10.1021/es8033044

Li, X., Pignatello, J. J., Wang, Y., \& Xing, B. (2013). New insight into adsorption mechanism of ionisable compounds on carbon nanotubes. Environmental Science \& Technology, 47(15), 8334-8341.

Li, X., Liu, Y., Zhang, C., Wen, T., Wang, X. (2018). Porous $\mathrm{Fe}_{2} \mathrm{O}_{3}$ microcubes derived from metal organic frameworks for efficient elimination of organic pollutants and heavy metal ions. Chemical Engineering Journal, 336, 241-252. https://doi.org/10.1016/j.cej.2017.11.188

Mauter, M. S., \& Elimelech, M. (2008). Environmental applications of carbon-based nanomaterials. Environmental Science and Technology, 42(16), 5843-5859. https://doi.org/10.1021/es8006904 
Liu, X., Zhang, H., Ma, Y., Wu, X., Meng, I., Guo, Y., Yu, G., \& Liu, Y. (2013). Graphene-coated silica as a highly efficient sorbent for residual organophosphorus pesticides in water. Journal of Materials Chemistry A, 1, 1875-1884. https://doi.org/10.1039/C2TA00173J

Pahigian, J. M., \& Zuo, Y. (2018). Occurrence, endocrine related bioeffects and fate of bisphenol A chemical degradation intermediates and impurities. A review. Chemosphere, 207, 469480. https://doi.org/10.1016/j.chemosphere.2018.05.117

Prossnitz, E. R., \& Barton, M. (2014). Estrogen biology: new insights into GPER function and clinical opportunities. Molecular and Cellular Endocrinology, 389(1-2), 71-83. https://doi.org/10.1016/j.mce.2014.02.002

Radu, E., Stoica, R., Oprescu, E., Bolocan, I., Ion, I., \& Ion, A. C. (2016). Validation of a RP-HPLC method for the determination of bisphenol A at low levels in natural mineral water. Revista de Chimie, 67(2), 230-240.

Senin, R. M., Ion, I., Oprea O., Vasile, B., Stoica, R., Ganea, R., \& Ion, A. C. (2018). Sorption of bisphenol A (BPA) in aqueous solutions on fullerene C60. Revista de Chimie (Bucharest), 69(6), 1309-1314.

Song, S., Huang, S., Zhang, R., Chen, Z., Wen, T., Wang, S., Hayat, T., Alsaedi, A., \& Wang, X. (2017). Simultaneous removal of $\mathrm{U}(\mathrm{VI})$ and humic acid on defective TiO investigated by batch and spectroscopy techniques. Chemical Engineering Journal, 325, 576-587. https://doi.org/10.1016/j.cej.2017.05.125

Su-Zhen, H., Holger, M., \& Chen-Xu, W. (2014). Aggregation of fullerene (C60) nanoparticle: A molecular study. Chinese Physics B, 23(4), 048201-1-048201-4.

Wang, L., Hou, L., Wang, X., \& Chen, W. (2014). Effects of the preparation method and humic acid modification on the mobility and contaminant-mobilizing capability of fullerene nanoparticles. Environmental Science Process Impacts, 16, 12821289. https://doi.org/10.1039/c3em00577a

Yang, K., \& Xing, B. (2010). Adsorption of organic compounds by carbon nanomaterials in aqueous phase: Polanyi theory and its application. Chemical Review, 110, 5989-6008. https://doi.org/10.1021/cr100059s

Yang, Q., Li, X., Chen, G., Zhang, J., \& Xing, B. (2016). Effect of humic acid on sulfamethazine adsorption by functionalized multi-walled carbon nanotubes in aqueous solution: mechanistic study. RSC Advanced, 6, 15184-15191. https://doi.org/10.1039/C5RA26913J

Yang, Y., Nakada, N., Nakajima, R., Yasojima, M., Wang, C., \& Tanaka, H. (2013). pH, ionic strength and dissolved organic matter alter aggregation of fullerene C60 nanoparticles suspensions in wastewater. Journal of Hazardous Materials, 244245, 582-587. https://doi.org/10.1016/j.jhazmat.2012.10.056

Zhang, C., Liu, Y., Li, X., Chen, X., \& Wang, X. (2018). Highly uranium elimination by crab shells-derived porous graphitic carbon nitride: Batch, EXAFS and theoretical calculations. Chemical Engineering Journal, 346, 406-415. https://doi.org/10.1016/j.cej.2018.03.186

Zhang, L., Zhang, Y., Lin, X., Yang, K., \& Lin, D. (2014). The role of humic acid in stabilizing fullerene (C60) in suspensions. Applied Physics and Engineering, 15(8), 634-642. https://doi.org/10.1631/jzus.A1400115

Zhang, S., Shao, T., Bekaroglu, S. S. K., \& Karanfil, T. (2010). Adsorption of synthetic organic chemicals by carbon nanotubes: Effects of background solution chemistry. Water Resources, 44(6), 2067-2074.

Zhao, J., Wang, Z., Ghosh, S., \& Xing, B. (2014). Phenanthrene binding by humic acid-protein complexes as studied by passive dosing technique. Environmental Pollution, 184, 145-153. https://doi.org/10.1016/j.envpol.2013.08.028

Zhou, L., Zhu, D., Zhang, S., \& Pan, B. (2015). A settling curve modeling method for quantitative description of the dispersion stability of carbon nanotubes in aquatic environments. Journal of Environmental Sciences, 29, 1-10. https://doi.org/10.1016/j.jes.2014.05.054

Zhou, M., Luo, L. L., Zhong, S. X., Yang, J. Y., \& Chen, J. R. (2014). Progress of graphene-based composites for adsorption of pollutants in wastewater. Applied Mechanics and Materials, 455, 7-10.

https://doi.org/10.4028/www.scientific.net/AMM.455.7

Zou, M. Y., Zhang, J. D., Chen, J. W., \& Li, X. H. (2012). Simulating adsorption of organic pollutants on finite single walled carbon nanotubes in water. Environmental Science and Technology, 46(16), 8887-8894. https://doi.org/10.1021/es301370f 